\title{
BR-440 em Juiz de Fora (MG) e seus desdobramentos: Uma análise revisional
}

\section{narrativa}

\author{
BR-440 in Juiz de Fora (MG) and its developments: A narrative revision analysis \\ BR-440 em Juiz de Fora (MG) y sus desarrollos: Un análisis de revisión narrativa
}

Recebido: 28/04/2021 | Revisado: 05/05/2021 | Aceito: 09/05/2021 | Publicado: 26/05/2021

Vinícius Tavares Barros

ORCID: https://orcid.org/0000-0002-7662-2338 Universidade Federal de Juiz de Fora, Brasil E-mail: vinicius.tavares@arquitetura.ufjf.br

Fabio de Oliveira Sanches

ORCID: https://orcid.org/0000-0001-5629-8350 Universidade Federal de Juiz de Fora, Brasil

E-mail: fsanches.73@gmail.com

Cascio Raposo Machado

ORCID: https://orcid.org/0000-0003-2162-5440

Universidade Federal de Juiz de Fora, Brasil E-mail: cascio.raposo@arquitetura.ufjf.br

\begin{abstract}
Resumo
O processo de construção da BR-440 em Juiz de Fora - MG possui vigência por um considerável período de tempo (doze anos). A obra, iniciada no ano de 2009 a qual é de responsabilidade do Departamento Nacional de Infraestrutura e Transporte (DNIT), até hoje enfrenta entraves para a sua conclusão, principalmente por conta de questões ambientais relacionadas ao traçado da via e à canalização e cobertura do córrego São Pedro, fomentando debates a respeito de seu real benefício ao município. Assim, o objetivo deste artigo é discutir (i) a inserção da BR-440 no contexto atual e (ii) como a referida infraestrutura é percebida pela população local, bem como por quem atuou em sua implementação. $\mathrm{O}$ estudo baseou-se em uma análise revisional narrativa, tendo como base da dados notícias do jornal local Tribuna de Minas, por meio de uma análise de reportagens publicadas ao longo da última década e que levantam discussões técnicas e sociais sobre a construção da rodovia. Os resultados apontam que os problemas advindos de sua construção ainda geram muitas discussões jurídicas e políticas, além de transtornos à população que reside próximo à via.
\end{abstract}

Palavras-chave: Rodovia; Via São Pedro; Construção; Infraestrutura.

\begin{abstract}
The construction process of the BR-440 in Juiz de Fora - MG is valid for a considerable period of time (twelve years). The work, which began in 2009, which is the responsibility of the National Department of Infrastructure and Transport (DNIT in portuguese), still faces obstacles to its completion, mainly due to environmental issues related to the layout of the road and the channeling and coverage of the São Pedro stream, fostering debates about its real benefit to the municipality. Thus, the objective of this article is to discuss (i) the insertion of BR-440 in the current context and (ii) how the referred infrastructure is perceived by the local population, as well as by those who acted in its implementation. The study was based on a narrative revision analysis, based on news from the local newspaper Tribuna de Minas, through an analysis of reports published over the last decade that raise technical and social discussions about the construction of the highway. The results show that the problems arising from its construction still generate many legal and political discussions, as well as inconvenience to the population that lives close to the road.
\end{abstract}

Keywords: Road; Via São Pedro; Construction; Infrastructure.

\section{Resumen}

El proceso de construcción de la BR-440 en Juiz de Fora - MG tiene una vigencia considerable (doce años). La obra, iniciada en 2009, que está a cargo del Departamento Nacional de Infraestructura y Transporte (DNIT), aún enfrenta obstáculos para su finalización, principalmente por cuestiones ambientales relacionadas con el trazado de la vía y la canalización y cobertura del arroyo São Pedro, lo que propicia debates sobre su beneficio real para el municipio. Así, el objetivo de este artículo es discutir (i) la inserción de la BR-440 en el contexto actual y (ii) cómo la referida infraestructura es percibida por la población local, así como por quienes actuaron en su implementación. El estudio se basó en un análisis de revisión narrativa, a partir de noticias del diario local Tribuna de Minas, a través de un análisis de reportajes publicados durante la última década que plantean discusiones técnicas y sociales sobre la construcción 
de la carretera. Los resultados muestran que los problemas derivados de su construcción aún generan muchas discusiones legales y políticas, así como molestias a la población que vive cerca de la carretera.

Palabras clave: Carretera; Via São Pedro; Construcción; Infraestructura.

\section{Introdução}

Baseando-se na ideia de modernizar o país, o governo federal promoveu, a partir da metade do século XX, a implementação de um sistema rodoviário massivo no Brasil. Por conta do desenvolvimento dessa política de integração nacional, por meio de rodovias interligando o país houve aumento no número de veículos circulando pelo território brasileiro. Consequentemente, esse modelo acabou influenciando a maneira como as cidades são planejadas, de modo que tornou-se predominante em nossa cultura (Vasconcellos, 2001).

Juntamente a esse cenário, o crescimento das cidades fez com que o perímetro urbano coexistisse espacialmente com rodovias devido à expansão da malha urbana. Por conta disso, essa relação gera consequências positivas e negativas às áreas urbanizadas. Dentre os pontos positivos, destaca-se, por exemplo, a geração de empregos possibilitada pelas obras, a integração ao sistema logístico nacional ocasionado pelos avanços relacionados ao escoamento de produtos, além do transporte de passageiros potencialmente mais efetivo (Salomão et al., 2019). Entretanto, a divisão do espaço urbano, recortado pela rodovia, pode ser visto como um aspecto negativo para um determinado contexto regional (Castro et al., 2015). A Figura 1 apresenta, ao centro no sentido horizontal, a BR-440, na cidade de Juiz de Fora (MG), onde à esquerda situam-se a BR-040 (rodovia federal que interliga as cidades do Rio de Janeiro e Belo Horizonte) e a Represa de São Pedro. À direita, os bairros Jardim Casablanca e Nossa Senhora de Fátima.

Figura 1 - Imagem extraída do Google Earth Pro destacando a região onde se localiza a BR-440.

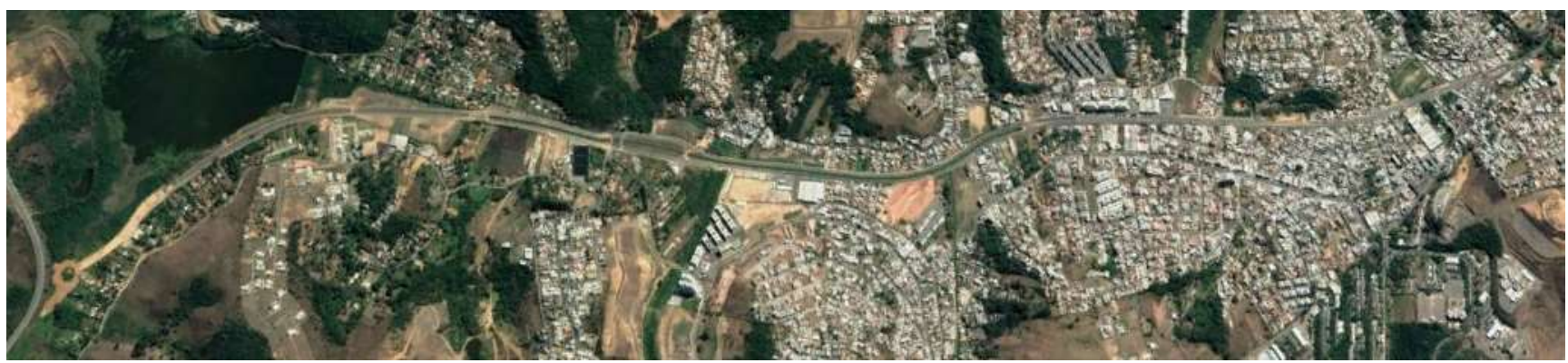

Fonte: Google Earth Pro (2020).

Com sua construção iniciada apenas em setembro de 2009 (Vanini, 2012), a BR-440 foi originalmente idealizada pelo ex-prefeito Mello Reis durante os anos em que esteve à frente da prefeitura de Juiz de Fora (1977-1983). Inicialmente, o projeto propunha a conexão, através da nova via, da BR-040 com a BR-267, próximo ao bairro de Santa Terezinha. Entretanto, por conta de mudanças ocorridas na morfologia urbana ao longo dos anos, como o avanço da ocupação e consequente urbanização de áreas como o Vale do Ipê, o projeto original ficou inviável e então, como alternativa, foi proposto um traçado ligando a BR-040 ao Campo Nova União (Tribuna, 2017).

A presente pesquisa procura analisar, sob a ótica da população, bem como dos órgãos públicos e privados envolvidos com o empreendimento, o papel estratégico atual da BR-440, também conhecida como Via São Pedro, no sentido de fomentar o aprofundamento das discussões a respeito da referida obra de infraestrutura, em torno de seu projeto e ação propositiva. $\mathrm{O}$ artigo tem como objetivo atualizar o panorama contextual da BR-440 por meio de uma análise revisional narrativa sob a perspectiva do processo que envolve a sua construção. 


\section{Metodologia}

Inicialmente, a pesquisa utilizou o quadro proposto por Cook, Mulrow e Haynes (1997) e traduzido por Botelho, Cunha e Macedo (2011) como ponto de partida para o desenvolvimento do estudo. No quadro, os autores estabelecem seis itens: (a)questão, (b)fonte, (c)seleção, (d)avaliação, (e)síntese e (f)inferências; E então propõem diferenciar a revisão narrativa e a revisão sistemática a partir do modo como cada metodologia responde a cada item. A seguir, o Quadro 1 relaciona os itens supracitados à revisão narrativa:

Quadro 1 - direcionamentos à revisão narrativa.

\begin{tabular}{|c|c|}
\hline \multicolumn{2}{|c|}{ Revisão Narrativa } \\
\hline Item & Direcionamento \\
\hline Questão de pesquisa & Ampla \\
\hline Fonte & Frequentemente não especificada, potencialmente com viés \\
\hline Seleção & Variável \\
\hline Avaliação & Variável \\
\hline Síntese & Qualitativa \\
\hline Inferências & Às vezes baseadas em resultados de pesquisa clínica \\
\hline
\end{tabular}

Fonte: Cook, Mulrow e Haynes (1997) e Botelho, Cunha e Macedo (2011).

Nesse sentido, primeiramente procurou-se formular uma questão ampla de pesquisa: afinal, o que é a BR-440? Na etapa a seguir, foram analisadas as fontes de pesquisa e base de dados (o estudo baseou-se em notícias do jornal Tribuna de Minas), seguido pela seleção e posterior avaliação dos textos selecionados. Dessa forma, buscou-se por meio de tais procedimentos, uma síntese qualitativa do material analisado.

A metodologia utilizada também baseou-se nas estratégias apresentadas por Moura et al. (2020) que, a partir da escolha de sua base de dados, determinou (i) critérios de inclusão e (ii) critérios de exclusão. Desse modo, a base de dados escolhida foi o acervo online do jornal Tribuna de Minas, de Juiz de Fora. Essa opção se deu pelo grande número de publicações narrando eventos relativos a BR-440.

Foram considerados como critérios de inclusão os termos (1) BR-440, (2) 440 e (3) via São Pedro por estarem presentes no título da reportagem, no texto da reportagem e o ano da publicação, entre 2011 e 2020. Por sua vez, os critérios de exclusão foram: (1) publicações anteriores ao período mencionado e que (2) não possuíssem em seu título nenhum dos termos supracitados.

\section{Resultados e Análises}

\subsection{Resultados Preliminares}

O Quadro 2 apresenta o número de reportagens encontradas e o número de reportagens selecionadas, a partir dos critérios citados no tópico anterior: 
Quadro 2 - Número de publicações selecionados nas bases de dados do jornal Tribuna de Minas.

\begin{tabular}{|c|c|c|}
\hline \multirow{2}{*}{ Base de pesquisa } & \multicolumn{2}{|c|}{ Publicações } \\
\cline { 2 - 3 } & Antes da triagem & Após a triagem \\
\hline Tribuna de Minas & 43 & 15 \\
\hline Total de publicações selecionadas & \multicolumn{2}{|c|}{15} \\
\hline
\end{tabular}

Fonte: Autores (2021).

Desse modo, a pesquisa baseou-se em quinze (15) reportagens para ser desenvolvida, sendo duas (2) referentes ao ano de 2012, duas (2) ao ano de 2014, uma (1) ao ano de 2016, duas (2) ao ano de 2017, quatro (4) ao ano de 2018, três (3) ao ano de 2019 e uma (1) ao ano de 2020.

\subsection{Análise}

\subsubsection{Contexto inicial}

Ao longo dos anos, o projeto levantou inúmeros questionamentos como, por exemplo, o fato de possuir parte de seu traçado situado dentro de áreas de proteção ambiental, sendo que documentos relativos ao licenciamento ambiental da obra embasado pela lei 6.938/81 que dispõe sobre a política nacional do meio ambiente - ainda não haviam sido apresentados para que tal ação fosse executada. Além disso, diversas irregularidades no tocante às verbas disponibilizadas para a obra foram identificadas, tendo sido alvo de denúncias na câmara e nos tribunais (Tribuna, 2017). Por conta dessas irregularidades e trâmites para que fossem solucionadas, as obras mantiveram-se paradas de 2012 até meados de 2019 (Bernadete, 2019c).

A análise a respeito do licenciamento ambiental que, a princípio, seria realizado pela Superintendência Regional de Meio Ambiente da Zona da Mata (Supram-ZM), em Ubá, foi repassado a Superintendência de Projetos Prioritários (SUPPRI), situado em Belo Horizonte. Somado a essa questão, o Tribunal de Contas da União (TCU) determinou a suspensão da obra devido à ausência de licitação pública para a escolha da empresa que executaria a obra. Sendo assim, em 2015 foi realizada licitação para seleção de empresa responsável pela execução na qual a EMPA S/A, empresa que já atuava anteriormente no projeto, foi a vencedora (Valente, 2017).

\subsubsection{Relação com a sociedade}

A construção da BR-440 no bairro São Pedro, zona oeste de Juiz de Fora, tem enfrentado resistência por parte da população local. O arrastado processo para conclusão da obra há muito tempo causa transtornos aos residentes da região. Em reportagem publicada por Vanini (2012), muitos são os relatos a respeito de problemas ocasionados pela falta de sinalização e equipamentos públicos para uso de quem passa pela via. Dentre as inúmeras questões citadas por usuários, a ausência de fiscalização, a via em "mão inglesa" mal sinalizada, os confusos cruzamentos de ruas com a via e a péssima sinalização são alguns dos principais pontos levantados, restando apenas o bom senso a quem passa pelo local (Bernadete, 2020). As Figuras 2 e 3 a seguir ilustram o confuso trânsito na via, próximo aos bairros Jardim Casablanca e Nossa Senhora de Fátima. 
Figura 2 - Ausência de placas de sinalização e marcações no asfalto e via parcialmente bloqueada.

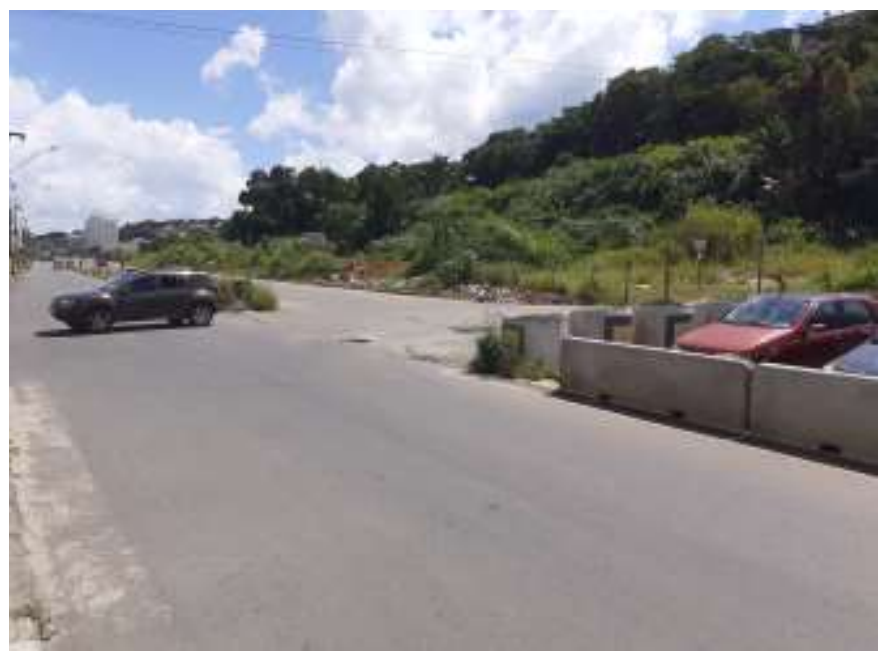

Figura 3 - Veículos realizando conversão à Avenida Pedro Henrique Krambeck, paralela à BR-440.

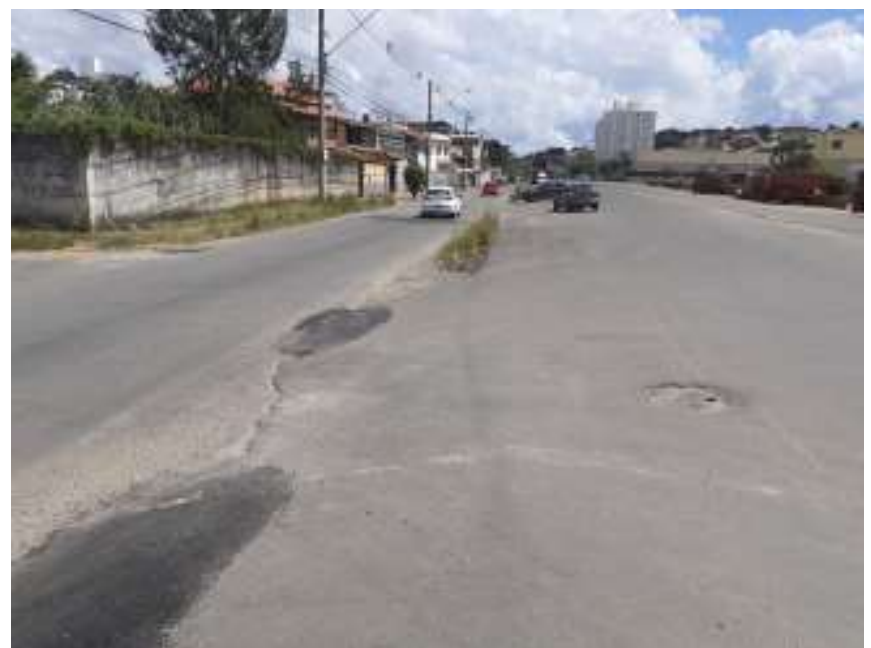

Fonte: Autores (2021).

A falta de uma resolução definitiva sobre o empreendimento associado ao crescimento urbano e populacional da região fez com que a população local se apropriasse da via, adequando o uso às suas necessidades. O comércio local também sofreu consequências do moroso processo de implantação da rodovia na região. Segundo Tribuna (2012), comerciantes que possuíam estabelecimentos na Avenida Pedro Henrique Krambeck (Via São Pedro/BR-440) estavam enfrentando problemas por conta da mudança no trânsito. Devido às alterações feitas, o número de clientes diminuiu em alguns pontos obrigando os comerciantes a mudarem de endereço e, em alguns casos, fechando o referido estabelecimento.

Diante dos problemas iniciais já citados neste estudo, houve por parte da sociedade civil três petições protocoladas questionando a legalidade da BR-440. Por meio dessa iniciativa, a população buscava discutir alternativas de uso a via, de modo que o interesse comum seria o de impedir que o local não se transformasse numa rodovia federal. Tal preocupação se dava por conta das possíveis consequências negativas que poderiam ser geradas, como o alto fluxo de veículos pesados e a divisão do bairro (Valente, 2014a).

De acordo com Valente (2014b) a BR-440 é vista como um potencial ponto para atividades de lazer dentro do município. Por essa razão, o ex-prefeito Bruno Siqueira propôs a municipalização da rodovia, visando implementar ciclovia, área para caminhada e lazer. A ideia baseia-se na intenção de que a via seja um equipamento integrador de bairros na cidade, além do fato de que a população impactada pela obra observa com temor a possibilidade de, ao se tornar um rodovia federal, a região seja afetada de maneira negativa. Desse modo, a via deixaria de pertencer a União. À época, o ex-prefeito também disse que lutaria para impedir que no local passassem veículos pesados e reiterou que estava ao lado da comunidade. As figuras 4 e 5 mostram a via próxima da região da Represa de São Pedro e da BR-040. 
Figura 4 - Região da via que pessoas utilizam como local de lazer.

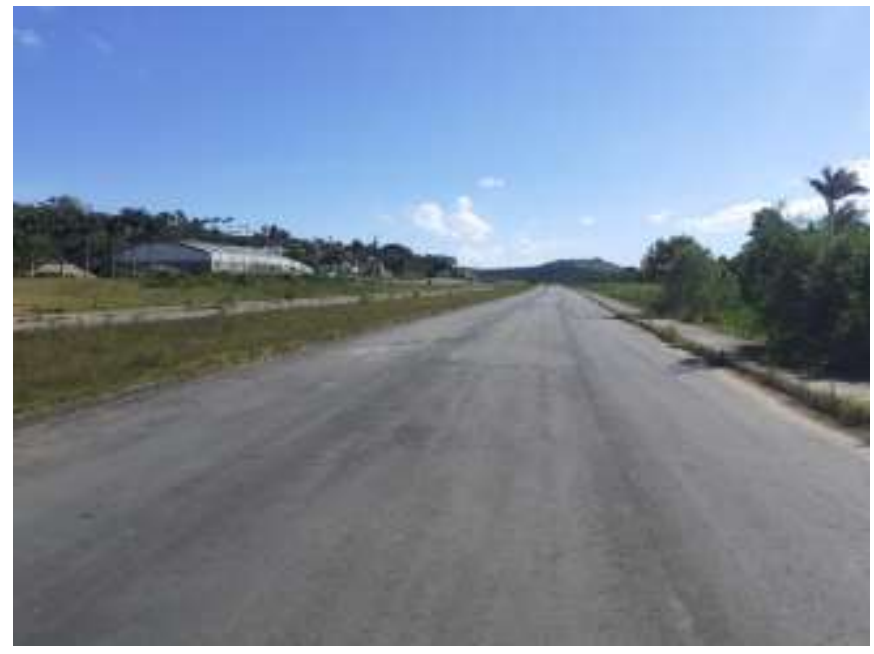

Figura 5 - Região da via próxima a represa (à esquerda) utilizada pela população como espaço público de lazer.

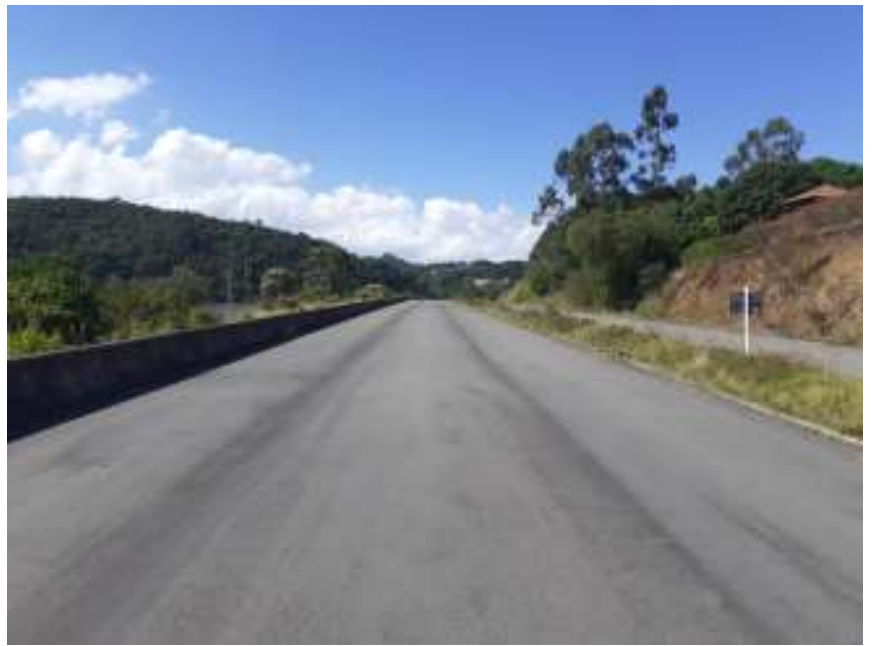

Fonte: Autores (2021).

Há algum tempo, a região da via próxima à represa é bastante utilizada pela população como local para atividades físicas ao ar livre bem como provas de Triátlon (Sympla, 2020), dentre outras modalidades. Dessa forma, a ideia de legitimar essa função ao local é justificada, além de, eventualmente, dar maior segurança aos pedestres e ciclistas que atualmente competem por espaço com veículos em certos pontos da via.

De acordo com Valente (2016), por determinação do DNIT através da portaria nº 1.410 de cinco de agosto de 2016, 107 imóveis estavam em processo de desapropriação. A reportagem ainda afirma que a rodovia abrange uma faixa de domínio de trinta metros e, desse modo, os imóveis situados dentro dessa faixa deveriam ser desapropriados. Somados, a área total desapropriada chega a aproximadamente cinquenta e um mil metros quadrados. Dentre as reclamações dos donos de imóveis na área estão questões relacionadas ao pagamento por parte do DNIT de um valor abaixo do praticado, além da mudança obrigatória para outros pontos que não possuam a mesma valorização da região ou a mesma visibilidade, no caso de estabelecimentos comerciais.

\subsubsection{Acontecimentos recentes}

Segundo Valente (2018), um acordo entre o Departamento Nacional de Infraestrutura de Transporte (DNIT) e Secretaria de Estado do Meio Ambiente e Desenvolvimento Sustentável (SEMAD) viabilizou, em 2018, a retomada no andamento das obras da BR-440. A autorização veio através de um Termo de Ajustamento de Conduta (TAC), porém as obras liberadas restringiam-se apenas às galerias de águas pluviais e à construção de passarelas devido a questões jurídicas e ambientais que ainda impediam o andamento de outras fases do empreendimento. A razão para essa restrição se deu porque essas obras independiam de outras autorizações, visto que não haveria "supressão de área verde ou de outorgas para a canalização, já concedidas". Até então, $44 \%$ da obra encontrava-se realizada a um custo de 58,1 milhões de reais, tendo sido 4,2 quilômetros concluídos.

Dentre as inúmeras polêmicas envolvendo o projeto, questões relativas a canalização do córrego São Pedro também preocupam especialistas e a população diretamente impactada devido a eventuais transtornos que podem ser causados por erros projetuais relacionados ao dimensionamento das galerias pluviais associado ao volume de água proveniente das chuvas. De acordo com informações disponibilizadas pelo professor Cézar Barra da UFJF, Bernadete (2018b) apresenta razões que motivam a preocupação por conta dessa canalização. Dentre as questões trazidas, destacam-se o fato de que esse tipo de obra 
impede a infiltração da água no solo e aumenta a velocidade do fluxo, podendo causar problemas. Além disso, a ausência de luz solar e oxigenação fazem com o córrego perca as formas de vida que ali habitavam e, de acordo com o professor Cézar, "o córrego vire um escoador de esgoto". A figura 6 compara como era o córrego antes e após as obras da BR-440. A imagem superior é de 2005 e a inferior, 2020.

Figura 6 - Imagem comparativa extraída do Google Earth Pro mostrando o córrego São Pedro antes e após as obras da BR440
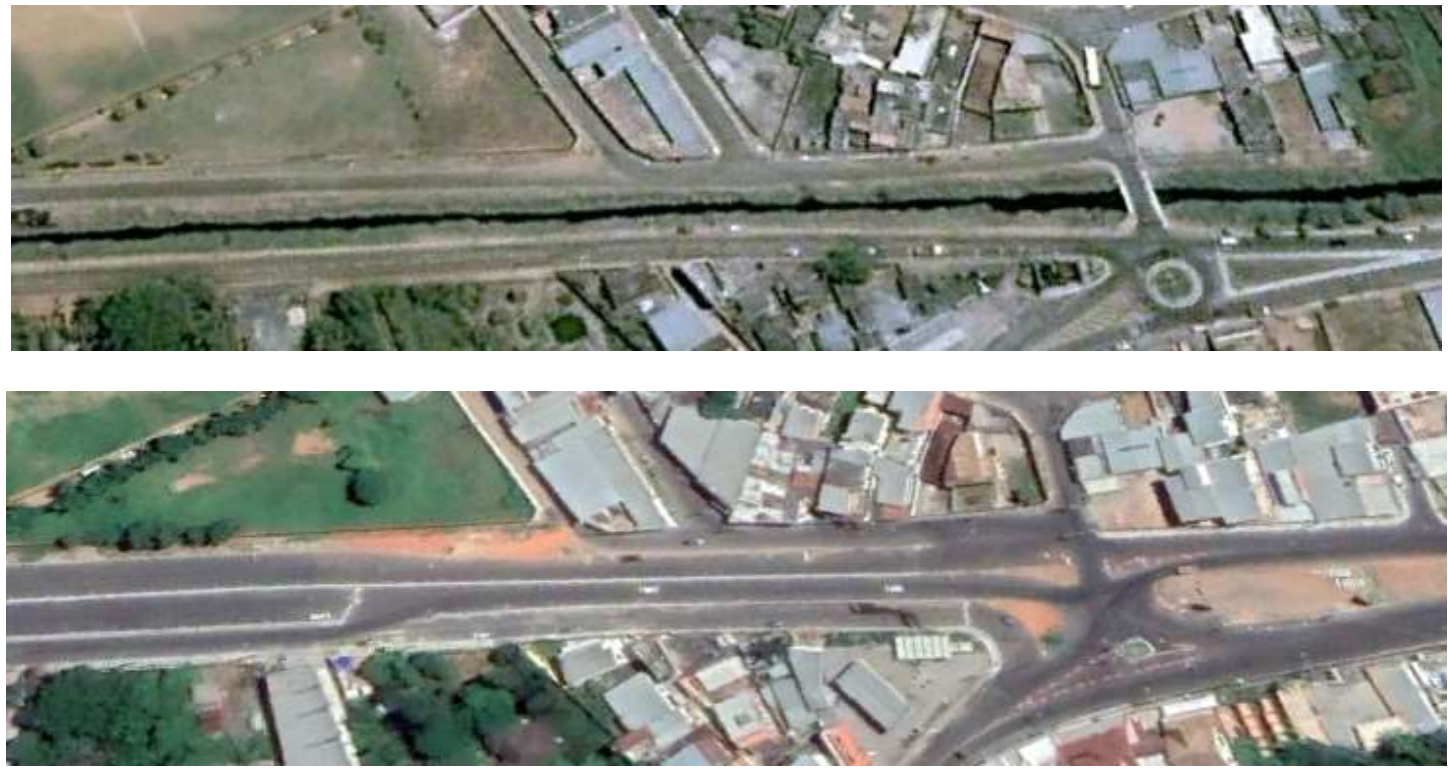

Fonte: Google Earth Pro (2021).

Ainda a respeito da canalização e do eventual cenário problemático que sua construção pode vir a causar, Oliveira Filho e Mendes (2018) afirmam que a criação desses canais baseia-se "no princípio de aumentar a velocidade de escoamento das águas precipitadas, através da implementação de medidas de controle estrutural como a retificação e a canalização dos cursos d'água em estrutura fechada (galeria), na qual o rio é suprimido da paisagem." Ainda de acordo com os autores, "essas reformas estruturais afastam os riscos de inundações". Entretanto, esse conceito desconsidera o quão complexa é a drenagem urbana e, como consequência, trechos não canalizados a jusante podem sofrer as consequências desses grandes volumes de água que chegam rapidamente (Oliveira Filho \& Mendes, 2018).

Apesar da restrição inicial à apenas serviços de canalização, Bernadete (2018a) trouxe informações a respeito da possibilidade das obras retornarem integralmente por conta do "avanço na análise da regularização ambiental, necessária para retomada das intervenções no local". De acordo com a reportagem, "técnicos da Superintendência de Projetos Prioritários (SUPPRI) realizaram vistoria na área de construção da BR-440, com o objetivo de coletar informações para subsidiar o processo". Entretanto, esse processo se prolongaria por alguns meses devido à dependência da apresentação de documentos pelo DNIT caso fossem solicitados.

Assim sendo, em meados de 2019 a obra foi reiniciada após ser devidamente licenciada (Bernadete, 2019a). De acordo com Bernadete (2019b), dentre os serviços a serem executados estavam a pavimentação, drenagem e obras complementares. Entretanto, em reportagem de dezembro, segundo Borges (2019), o DNIT, órgão responsável pelo projeto e a Secretaria de Transporte e Trânsito (SETTRA) tiveram dissonâncias por conta do binário que estava sendo construído entre as avenidas Presidente Costa e Silva e Pedro Henrique Krambeck e a rua José Lourenço Kelmer. A SETTRA solicitou ao DNIT intervenções para adequação do trevo do bairro Jardim Casablanca ao binário em construção, porém o pedido foi negado. 


\section{Considerações Finais}

A partir do conteúdo pesquisado e apresentado foi possível obter um panorama atualizado sobre fatos relativos à BR440 durante a última década. Dentro das esferas jurídica e política, pôde-se concluir que muitos fatores suprimidos nas fases iniciais de projeto, consequentemente, acarretaram problemas que permaneceram em pauta por um longo período, como as questões de licenciamento ambiental que só tiveram um desfecho em 2019, a ausência de licitação pública, acarretando ainda mais atrasos nas obras, além da disputa em relação a quem caberia a responsabilidade de administrar a via.

Além disso, por se tratar de um projeto de grande escala, no qual um número significativo de pessoas será afetado, é fundamental que os moradores da região sejam ouvidos por meio de audiências públicas e, que a tomada de decisão seja feita de forma integrativa, levando em consideração a opinião e o bem-estar da sociedade a ser afetada direta e indiretamente. Entretanto, durante a revisão realizada, foi latente a percepção do caráter impositivo tanto por parte da EMPA S/A, empresa responsável pela construção da via quanto do poder público.

O caso da BR-440 configura-se como um claro exemplo em que as decisões tomadas pelos responsáveis pelo poder público não consideraram as condições de realidade, dos problemas e das demandas dos atores sociais diretamente envolvidos no projeto de seu traçado. Também não se considerou a ampla gama de aspectos socioambientais envolvidos nas transformações espaciais decorrentes dessas obras.

Evidente que soluções são (e foram) propostas por parte dos diversos agentes envolvidos. No entanto, os erros procedimentais cometidos nas fases iniciais (de planejamento, falta de audiências, de execuções etc.) além de trazerem morosidade à obra, certamente oneraram substancialmente os seus custos, além dos demais transtornos descritos neste trabalho.

Dessa forma, o presente artigo procurou resgatar e refletir sobre os recentes fatos que envolvem a presente questão no município de Juiz de Fora, ocorridos durante a última década e fomentando a sociedade civil a participar do debate a respeito do referido empreendimento, visto que sua construção alterará radicalmente a dinâmica de mobilidade dentro da cidade.

\section{Agradecimentos}

Ao ProAC/UFJF pela oportunidade, ao professor José Alberto Barroso Castañon por fomentar e apoiar o desenvolvimento do referido tema e aos familiares e amigos por todo suporte dado.

\section{Referências}

Bernadete, L. (2018a). Avança processo de retomada de obras na BR-440. https://tribunademinas.com.br/noticias/cidade/17-08-2018/avanca-processo-deretomada-das-obras-na-br-440.html

Bernadete, L. (2019a). Famílias terão partes de imóveis desapropriadas na BR-440. https://tribunademinas.com.br/noticias/cidade/23-04-2019/empreiteiraconfirma-necessidade-de-desapropriar-imoveis-na-cidade-alta.html

Bernadete, L. (2020). Obras da BR-440 estão novamente interrompidas. https://tribunademinas.com.br/noticias/cidade/10-09-2020/obras-da-br-440-estaonovamente-interrompidas/html

Bernadete, L. (2018b). Obras da BR-440 poderão ser integralmente retomadas. https://tribunademinas.com.br/noticias/cidade/28-07-2018/obras-da-br-440poderao-ser-integralmente-retomadas.html

Bernadete, L. (2019b). Veículos já podem circular em trechos da BR-440. https://tribunademinas.com.br/noticias/cidade/16-06-2019/veiculos-ja-podemcircular-em-trechos-da-br-440.html

Borges, G. F. (2019). Impasse entre Prefeitura e Governo federal pode inviabilizar binário na Cidade Alta. https://tribunademinas.com.br/noticias/cidade/2212-2019/impasse-entre-prefeitura-e-governo-federal-pode-inviabilizar-binario-na-cidade-alta.html

Botelho, L. L. R., Cunha, C. C. de A., \& Macedo, M. (2011). O método da revisão integrativa nos estudos organizacionais. Gestão e Sociedade. 5(11), 121136.

Brasil. (2016). https://www.gov.br/dnit/pt-br/assuntos/planejamento-e-pesquisa/desapropriacao-e-reassentamento/dup-2016/DUPN1.410BR440MG.pdf/view 
Research, Society and Development, v. 10, n. 6, e16310615554, 2021

(CC BY 4.0) | ISSN 2525-3409 | DOI: http://dx.doi.org/10.33448/rsd-v10i6.15554

Brasil. Lei No 6.938/81 - Da Política Nacional do Meio Ambiente, Brasília De 31 De Agosto De 1981.

Castro, A. A. B. de C., Melo, R. A. de, Silveira, J. A. R. da, Silva, G. J. A., \& Lapa, T. A. (2015). Interfaces rodoviário-urbanas no processo de produção das cidades: estudo de caso do contorno rodoviário de João Pessoa, PB, Brasil. Ambiente Construído, Porto Alegre, 15(3), 175-199.

Cook, D. J., Mulrow, C. D., \& Haynes, R. B. (1997). Systematic reviews: synthesis of best evidence for clinical decisions. Annals of Internal Medicine, Philadelphia, 126(5), 376-380.

Moura, A. B. R. et al. (2020). Atendimento odontológico para pacientes com necessidades especiais: uma revisão de literatura. Research, Society and Development, Campina Grande, 9(8), 1-16.

Oliveira Filho, G. R., \& Mendes, B. M. S. (2018). BR-440 e a questão da canalização. https://tribunademinas.com.br/opiniao/tribuna-livre/17-08-2018/br-440e-a-questao-da-canalizacao.html

Salomão, P. E. A., Santos, J. A. G., Ferreira, R. S., Gonçalves, B. B., Carvalho, P. H. V., \& Starich, R. (2019). Impactos ambientais gerados pela construção e operação de rodovias. Research, Society and Development, 8(10), 1-24.

Sympla. (2020). SSTS - Sprint \& Standard Triathlon Series PRIMEIRA ETAPA 2020. https://www.sympla.com.br/ssts---sprint--standard-triathlon-seriesprimeira-etapa-2020_776250

Tribuna. (2012). Comerciantes reclamam de demora nas obras da 440. https://tribunademinas.com.br/noticias/economia/30-05-2012/comerciantes-reclamamde-demora-nas-obras-da-440.html

Tribuna. (2017). Velha novela. https://tribunademinas.com.br/opiniao/editorial/19-08-2017/velha-novela.html

Valente, E. (2018). Acordo permite retomada parcial de obras na BR-440. https://tribunademinas.com.br/noticias/cidade/11-05-2018/acordo-permiteretomada-parcial-de-obras-na-br-440.html

Valente, E. (2014a). Entidades contestam o destino da BR-440. https://tribunademinas.com.br/noticias/cidade/23-09-2014/entidades-contestam-o-destino-dabr-440.html

Valente, E. (2016). Mais de cem imóveis vão ser desapropriados. https://tribunademinas.com.br/noticias/cidade/24-04-2016/mais-de-cem-imoveis-vao-serdesapropriados-estudo-para-desapropriacao-custou-r-650-mil-abusos-de-carros-e-motos-em-via-inacabada.html

Valente, E. (2017). Obras da BR-440 estão emperradas há quase cinco anos. https://tribunademinas.com.br/noticias/cidade/18-08-2017/obras-da-br-440emperradas-ha-quase-cinco-anos.html

Valente, E. (2014b). Prefeito quer municipalizar BR-440. https://tribunademinas.com.br/noticias/cidade/25-09-2014/prefeito-quer-municipalizar-br-440.html

Vanini, E. (2012). Falta de sinalização leva insegurança à BR-440. https://tribunademinas.com.br/noticias/cidade/13-04-2012/falta-de-sinalizacao-levainseguranca-a-br-440.html

Vasconcellos, E. (2001). Transporte urbano, espaço e equidade: Análise das políticas públicas. Annablume. 